\title{
Architecture_MPS
}

\section{Photogenic Urban Landscapes: Towards an Intermedial Framework for Landscape Criticism in the Age of Social Media}

Erin Despard ${ }^{1, *}$

How to cite: Despard, E. 'Photogenic Urban Landscapes: Towards an Intermedial Framework for Landscape Criticism in the Age of Social Media.' Architecture_MPS, 2018, 14(1): 4, pp. 1-21. DOI: https://doi.org/10.14324/111.444.amps.2018v14i4.001.

Published: 05 December 2018

\section{Peer Review:}

This article has been peer reviewed through the journal's standard Editorial double blind peer review.

\section{Copyright:}

(C) 2018, The Author(s). This is an Open Access article distributed under the terms of the Creative Commons Attribution License (CC-BY) 4.0 https://creativecommons.org/licenses/by/4.0/, which permits re-use, distribution and reproduction in any medium, provided the original author and source are credited • DOI: https://doi.org/10.14324/111.444.amps.2018v14i4.001

\section{Open Access:}

Architecture_MPS is a peer-reviewed open access journal. 


\title{
Title: Photogenic Urban Landscapes: Towards an Intermedial Framework for Landscape Criticism in the Age of Social Media
}

\section{Author: Erin Despard}

\author{
Architecture_media_politics_society. vol. 14, no. 4 .
}

December 2018

Affiliation: Université de Sherbrooke, Canada

\begin{abstract}
Drawing on cultural geography, visual cultural studies and theories of media ecology, this essay lays out a framework for collaboration between media scholars, architects and critics, positioning photographic social media such as Instagram as a means for pursuing questions about the changing role of landscape in the visual mediation of urban social life and public culture. While buildings and urban infrastructure also have mediating functions, I focus on designed landscapes such as public parks because they mediate visual perception in a manner that is historically intertwined with that of photography. Responding to existing interest in the critical reading of landscape values as well as research on new photographic forms and practices arising from social media use, I suggest that we take seriously the idea that landscape is itself a form of media. Attending to its ongoing interactions with other media will enable us both to specify the nature of its intermediality in a given time and place, and open a new space for reflexivity and critique. Beginning with an
\end{abstract}




\section{Amps}

account of what is at stake in the visual mediation accomplished through urban landscapes on the one hand, and in the study of social media use on the other, I make a case for a critical, qualitative analysis of photographic content as opposed to quantitative analytics of the data associated with it. I then present an example of the kind of analysis I have in mind, drawing from an exploratory case study of photographs from Grand Park in Los Angeles (Rios Clementi Hale). In the process, I flesh out the concept of intermediality as it pertains to designed landscapes and demonstrate the kinds of questions and pedagogical opportunities such an approach may open. 


\title{
Title: Photogenic Urban Landscapes: Towards an Intermedial Framework for Landscape Criticism in the Age of Social Media
}

\author{
Author: Erin Despard
}

Architecture_media_politics_society. vol. 14, no. 4 .

December 2018

\section{Introduction}

Critical and historical work by landscape architects, art historians and other scholars has shown the multitude of ways in which designed landscapes act on visual perception. ${ }^{1}$ Or, given the complexity of contributing elements at any given site, perhaps it is more precise to say that they mediate the perceptual and socio-cultural processes shaping what is seen there. Some theorists of landscape have gone as far as to define landscape in general as media. For example, as W. T. Mitchell puts it, "landscape is itself a physical and multisensory medium (earth, stone, vegetation, water, sky, sound and silence, light and darkness, etc.) in which cultural values and meanings are encoded, whether they are put there by the physical transformation of a place in landscape gardening or architecture, or found in a place formed, as we say, 'by nature'." Taking additionally, its capacity, once culturally valued, to serve as a medium of social and economic exchange (e.g., via tourist and real estate markets), he concludes, "[it] is a medium in the fullest sense of the word." 2

At the same time, both the creation of landscape and perception of it are shaped by visual media. Not only do landscape architects employ a variety of visual media throughout the design process, even "natural" landscapes, to the extent that they are aesthetically appreciated (as opposed to traversed or worked), can be said to constitute a "way of seeing" produced in conjunction with a variety of visual technologies - from the art of perspective to the Claude glass and the camera. ${ }^{3}$ Landscape can thus be seen not only as a form of media, but as intermedial in its constitution - that is, inherently and continuously interactive with other media forms. What I want to suggest is that by taking the intermediality of landscape seriously, we might learn something about the socio-political dimensions of its visual effects. Attending in particular to the contribution that public landscapes make to multifaceted processes of visual mediation may provide a new avenue for thinking critically about 


\section{Amps}

what such landscapes do with respect to what it is possible to see, and be seen doing, in a given space.

Historically, public landscapes such as parks have served as spaces not only for social interaction, but also for the production of consensus over socio-cultural values. ${ }^{4}$ In the present, and especially in cities, where the terms of access to open space are increasingly well-defined, the public - that is, the specific bodies and activities that are seen to belong there - is made and remade through the use and visible appropriation of those spaces. ${ }^{5}$ Meanwhile, as Elen Deming has argued, the contribution of designed landscape to the shaping of such processes, makes it a privileged site for professional reflexivity and collective critique of otherwise concealed or taken-for-granted value systems. ${ }^{6}$ Toward this end, and especially to the extent that we wish public landscapes to function in a dynamic and inclusive manner, identifying how they make certain activities, qualities or ways of being together visible is important because it is also a way of seeing what has been made invisible.

\section{Urban Public Landscapes and Visual Social Media}

As work in visual cultural studies has shown, the question of visibility is always social and political as well as perceptual. ${ }^{7}$ Processes of visual mediation help to circumscribe what things, qualities, practices and relations are noticed and named, and what can be socially valued or, conversely, problematized and contested. Accordingly, as Ash Amin argues, the way public spaces look and feel has a profound if often underappreciated influence on collective culture:

billboards, public art, the design of space, public gatherings, the shape of buildings, the cleanliness of streets, the sounds and smells that circulate, the flows of bodies - come with strong sensory, affective and neurological effects. They shape public expectation, less by forcing automatic compliance, than by tracing the boundaries of normality and aspiration in public life. In our times, the projections in public space of the cultural cutting edge, social desire, matters of public concern, the uses of public space, norms of freedom and safety, and so on, are important summations of contemporary collective life, the measure of individual and social standing and possibility. ${ }^{8}$

The appearance and use of designed public landscapes is often specified and authoritatively sanctioned (to the extent that they are initiated, named, paid for and administered by governmental entities, or appear to be). However, the meanings associated with them and their cultural value are partly shaped through the active - if not necessarily thoughtful or even conscious - interpretation by users. As a starting point, such interpretations are influenced by the perspectives and assumptions users bring to the landscape, ${ }^{9}$ the way it is used, and the experiences to which it gives rise. ${ }^{10}$ However, it is also influenced by the way representations of it are incorporated in other media (e.g., in film, television, advertising images, real estate marketing, etc.), and how it is enrolled 
in individual and collective processes of valuation and meaning-making, such as those found in family photography and on social media. With the latter, certain collective interpretative activities are made available for critical analysis in new ways.

However, while there are some exceptions, ${ }^{11}$ most research on photographic social media to date has focused on what can be learned from patterns observed in the large quantities of data generated through its use - whether the metadata associated with uploaded photographs (e.g., geolocation, hashtags, the number of likes, followers and so on),${ }^{12}$ or metadata combined with visual data drawn from the photos themselves. ${ }^{13}$ As Schwarzer observes, writing about the potential utility of such methods in research on architecture and urbanism, "Analytics, not analysis, is required to make sense of their [the photographs] overwhelming quantity." 14 Indeed, such research can provide insight into the differing popularity of landmarks, buildings, public spaces or recurrent architectural features within a given city; ${ }^{15}$ the frequency and temporality according to which they are photographed (at certain times of day, or in rhythms coinciding with events); ${ }^{16}$ and the extent to which they contribute to a given city's "identity." 17 It may also provide insights into the way landscapes are valued by groups otherwise underrepresented in consultation processes (e.g., young people). ${ }^{18}$ According to Schwarzer, however, one thing that social media photographs do not really do is "merit advanced visual analysis from architects or architectural critics." This is because "The insights to be gleaned from them have less to do with judgments or shedding light on an architect's ideas than with quantitative assessments of how architecture figures within global socio-geographic patterns of image making." 19 However, a focus on analytics over analysis risks limiting the kinds of question that can be posed in research using social media, and may also miss opportunities for developing a more critical understanding of its socio-political functioning and perceptual effects.

Like all data, social media data is designed for specific purposes. Though these purposes vary somewhat between platforms and may evolve over time, they are universally commercial in nature. To restrict the use of social media data to the performance of the kind of analytics to which they are suited, is to accept severe limitations on the kinds of questions that can be posed. ${ }^{20}$ Given the way these limitations operate - for example, selecting out whole segments of a given population, ${ }^{21}$ or rendering the majority of a given data set unusable $^{22}$ - accepting them without explicitly interrogating them, can cause researchers to mistake what Wilson calls the representational for the representative. ${ }^{23}$ At the same time, as Wilson also points out, treating social media data as if it is social scientific data implicitly legitimizes the socio-cultural hegemony of the platforms in question. ${ }^{24}$

I would argue that, particularly where social media is used to depict and interpret public spaces, this hegemony is precisely what needs to be interrogated. As Marshall McLuhan most famously observed, all media operates in a manner which is socially and perceptually transparent, or environmental - in 


\section{Amps}

the sense that, the more we use it, the more it fades into the background of our awareness. ${ }^{25}$ Digital media may be doubly problematic from this perspective, for computer code generates social, spatial and perceptual effects at a distance from the site where it is produced, making it difficult to perceive not only the effects of social media, but also the constraints and interests that shape its form and functioning. Particularly where social media interacts with landscape, it has the capacity to imperceptibly shift and structure ways of seeing the world, according to priorities that, in the absence of critical interrogation, remain obscure. ${ }^{26}$ While we may hope for social media to enable a greater diversity in the interpretation of public landscapes, thus contributing to their openness and vitality, there is nothing to guarantee that this is actually what happens.

This is why a close, qualitative analysis of social media photographs has something to offer architectural research and criticism: it offers an opportunity to address critical questions about the functioning of social media in interaction with the built environment. For example, with respect to designed landscapes, what social groups and activities are made visible or invisible, and how? Is the increasing prominence of visual social media platforms in everyday interpersonal communication changing the socio-cultural functioning of such landscapes? Such questions point in turn to new reflexive and pedagogical opportunities for architects and their students, as well as a more general potential for the development of collective critical capacities in relation to urban landscapes and public spaces. From this perspective, platforms such as Instagram are not only a source of limitless data, but also a means of catching a glimpse of certain submerged aspects of landscape's participation in multifaceted processes of visual mediation.

A media ecological perspective is a promising starting point for addressing such questions because, while the term "media ecology" has seen a variety of uses over the years, ${ }^{27}$ a common premise is the interconnectedness of media forms. ${ }^{28}$ This premise is based on the observation, given to us most memorably in the work of McLuhan, that the functioning of any given media depends on, and in turn influences, other media forms. ${ }^{29}$ McLuhan was especially distrustful of new media forms, but acknowledged that the moment of their introduction could provide an opening for critical perception, since they could not help but interact with and alter the functioning of existing media; this would in turn provide a temporary visibility in the effects of both. As he put it, "[t] he moment of the meeting of media is a moment of freedom and release from the ordinary trance and numbness imposed by them on our senses." ${ }^{\prime 0}$ One way to exploit the critical perceptual possibilities contained in photographic social media while it is still relatively new, is to explore the ways in which specific platforms involve and implicate other media, such as designed landscapes. For example, how does their interaction facilitate the production and circulation of different kinds of photograph?

Consider for example, a photograph uploaded to Instagram which depicts a public park in Los Angeles (see Figure 1). The open lawn is covered with 


\section{Amps}
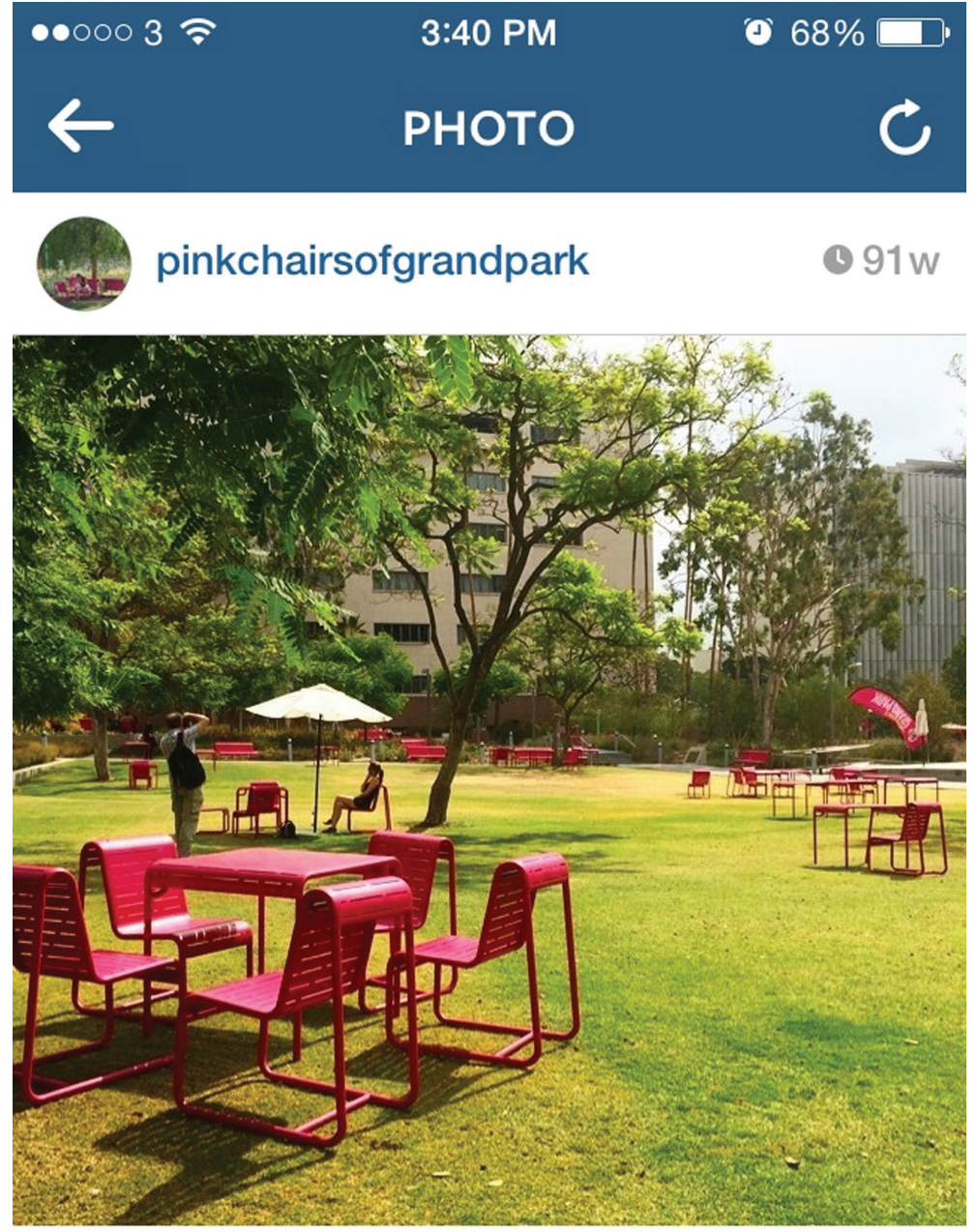

\section{priscindr}

by PhotoRepost

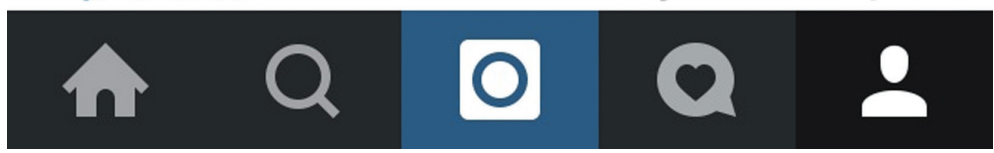

Figure 1: Screen shot of Instagram photograph, reposted by the author via @pinkchairsofgrandpark, originally by @priscindr.

bright pink chairs, the majority of which are empty. A man is taking a photograph of a woman sitting in one of the chairs. Like most photographs on Instagram, the associated hashtags and comments provide only a vague indication of context. As such, there are many possible readings of this 


\section{Amps}

photograph in relation to the social and cultural significance of the park. But I am more interested in what it does for the park, and what about the park has made it possible. If we attend to these questions, the relatively unreflective mode of photography enabled by Instagram may help us to see aspects of the landscape's capacity to mediate practices of looking - at least those that resonate with or amplify the social and perceptual functioning of Instagram. This may in turn provide a means of interrogating the social and political significance of similar or complementary perceptual effects between different media forms.

\section{Landscape and Photography}

Though the way we look at land is shaped by many visual practices and technologies, landscape has a special relationship to photography. Not only has the production and circulation of landscape photographs helped more people to see land as landscape, but the landscape "way of seeing" has shaped photographic technology and conventions. As Douglas Nickel writes, "Photography was born into a pre-existing, albeit incipient, notion of the photographic, one based on conceiving of the world as already containing an infinite number of latent pictorial compositions awaiting discovery". ${ }^{31}$ It is not insignificant then that "landscape" is the default format for photographs, requiring the camera to be turned on its side for portraits. ${ }^{32}$

In fact, because it is a broadly accessible and - in societies of the Global North - increasingly pervasive cultural practice, photography is particularly helpful in demonstrating the intermedial constitution of landscape in general. Particularly in the context of landscape tourism, landscape and cameras work together to prioritize particular views: that is, material interventions such as wilderness trails, scenic viewpoints, hedges and ha-ha's work with the representations of landscape found on postcards, websites, brochures and so on to teach people what to look for and appreciate. At the same time, the use of scenic landscapes as backdrops for photographs with a social content (e.g., family photos, selfies), and the circulation of those photographs among family members, on social media and so on, attests to and reinforces the cultural and social significance of such landscapes.

In the city, parks and other public landscapes - which have always been designed to mediate ways of seeing the city and the social activities privileged within it - are now often themselves mediated by websites, blogs and suites of social media accounts (e.g., Facebook, Twitter and Instagram), as well as by the circulation of photographs taken by visitors on the same platforms. Such developments make it possible to read urban landscapes as loci of mutually reinforcing processes of mediation. While some of these activities are explicitly promotional, I am most interested in what occurs more subtly between cameras, social media platforms and the landscapes themselves - that is, what hints at a shift in the socio-perceptual functioning of urban landscapes within a broader ecology of visual media forms. 
Some researchers have suggested that "networked photographies" (such as those associated with Instagram) function in a way that is different from existing photographic forms. This is due in part to the high volume and circumstances of their production (i.e., on location, in the midst of other activities), and also their presentation in a regularly updated stream, which gives them a relational or contextual significance that exceeds the boundaries of the photograph itself. ${ }^{33}$ It is also due to the association of the photographs with hashtags, which provide context through codified as opposed to narrative means. Such photographs can be seen to speak rather than represent their content. ${ }^{34}$ Much like the stock photography used in advertising images, they often present culturally engrained associations that do not need to be consciously interpreted. For the right audience (e.g., the account's followers), their meaning is culturally normative, and can be instantly recognized..$^{35}$

Given the historical reciprocity of influence between landscape and photography, and the increasing popularity of photographic social media platforms among park administrators and visitors alike, might we expect some designed landscapes to demonstrate a related change in functioning? The analysis which follows considers this possibility in relation to a large public park in Los Angeles.

\section{Grand Park}

Grand Park is a recently renovated historic park in downtown LA. Designed by Rios Clementi Hale Studios, it was paid for in part by the developers of a nearby condominium complex and is administered by The Music Center. Its mandate is to celebrate the city's cultural diversity and revitalize the previously crime and poverty-ridden downtown core. Since it re-opened in 2012, it has had a vibrant life on social media, thanks to the park's Facebook, Twitter and Instagram accounts as well as its enthusiastic reception by young Angelinos. Amateur and professional photographers have also found much to work with in the park's ample supply of tree-lined open spaces, bright pink furniture and spectacular architectural features (see Figure 2). Overlooked by a multi-level fountain that is colorfully lit at nighttime, the park unfolds in a pleasing succession of views down the hill towards City Hall.

From 2013 to 2015, I undertook an exploratory case study of photographs from Grand Park, as posted to Instagram. The aim of the study was to develop methods for critical analysis of the interactions between landscape and photographic social media. It began from the premise that the content of social media photographs could not be taken for granted as exclusively socially or aesthetically motivated, and that platform and landscape alike presented specific affordances and constraints that also shaped their content. It sought ways of incorporating some of the material, political and practical dimensions of photographic social media use in an analysis of photographic content. The published results combined socio-semiotic analysis of a specific landscape feature (as it functioned both in the landscape itself and in a subset 


\section{Amps}

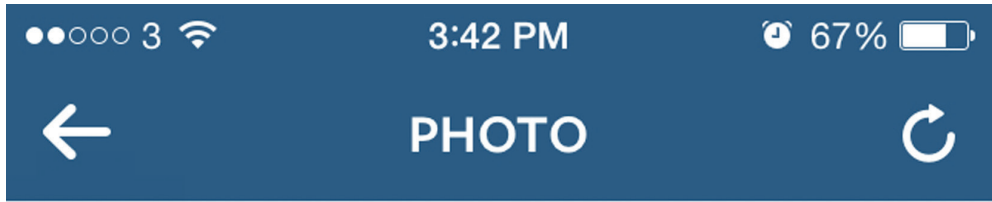

\section{pinkchairsofgrandpark

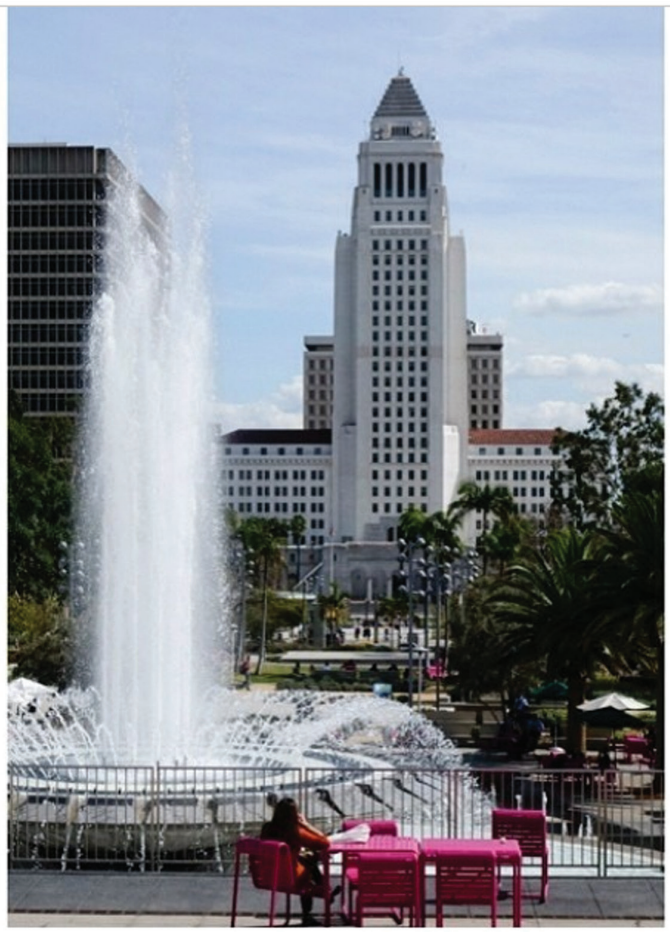

ㄴㄱ hosiephoto

by PhotoRepost

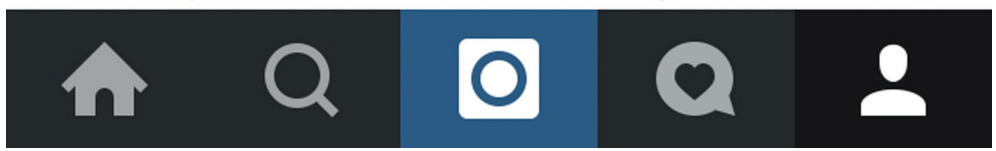

Figure 2: Screen shot of re-posted Instagram image, originally by @hosiephoto.

of the photographs from the sample considered), with a critical analysis of hashtags (as they functioned in association with those photographs as well as Instagram generally). ${ }^{36}$ In collaboration with a data architect, a rudimentary quantitative analysis of other metadata was also completed, but yielded little insight in relation to the rest of the analysis, and so was not included 
in the published results. ${ }^{37}$ Here I discuss some of my observations about the landscape feature and photographs selected for analysis - briefly treating the process of selection (perhaps the most vexing problem for qualitative research on social media images), but focusing on a translation of site-specific observations into more general ideas about the shifting intermediality of designed landscapes in the age of social media.

\section{A Critical Approach to Selecting Photographs for Qualitative Analysis}

After investigating several different ways to generate a set of photographs of Grand Park from Instagram, the set defined by \#grandparkla was chosen for study. In January of 2015, when the metadata was pulled from the API, this set held 2,407 photographs and videos. ${ }^{38}$ The majority of photographs featured the normal social media content - food, coffee, pets and people - meaning the landscape was often present merely as a backdrop, and was sometimes barely even visible as such. What was wanted, in contrast, were photographs of the landscape - or, more specifically, photographs of the landscape that were suggestive of Instagram's interaction with it. Further, it was decided that these should be selected in a manner that worked with the specific affordances and constraints of the platform, thus enabling questions about its functioning to be incorporated in the analysis. After some experimentation, an ad-hoc method was developed for generating a subset of landscape photographs using "normal" (i.e., platform-specific) practices of looking at photographs.

This method involved scrolling through the thumbnail search results for \#grandparkla on a phone, looking at the full-size photographs only when they clearly depicted a portion of the landscape. In the process, a particular element was identified which, between the effects of the camera (phone) and the landscape, was remarkable - that is, to draw on the etymology of the term, both highly noticeable and unique to the park. This element was the park's bright pink moveable chairs: common to many of the landscape photographs, it was also clearly visible even at the scale of thumbnails on a phone. While some of these photographs foregrounded the usual coffee, pets and people, with the chairs appearing in the background, many of them did not. In fact, the pink chairs seemed to provide a kind of short cut for finding photographs of the landscape, as opposed to photographs that had been produced incidentally in it. Given additionally, that the same color of pink appears in all promotional materials associated with the park (on and offline), the photographs in which the pink furniture was prominent seemed especially promising with respect to analyzing the interaction between the park's landscape and the visual media deployed on its behalf. Although Grand Park is not the first park to offer moveable furniture, its bright and unusual color - which shows up clearly in photographs, even at a distance - and its distribution throughout the park rather than in designated seating areas, is unique. A collection of photographs containing pink chairs (roughly 100 , or $4 \%$ of the total) was built by reposting 


\section{Amps}

them to a dedicated account, where it was then possible to look at them in relation to one another and make certain observations. ${ }^{39}$

I turn now to discussion of what the resulting analysis suggests about the intermediality of landscape as it pertains to photographic social media, and how attention to its effects in particular locations may open spaces for collective critique and professional reflexivity.

\section{Processes of Intermediation between Instagram and Landscape}

Grand Park's pink chairs are both in, and of, the landscape. They simultaneously signify leisurely social activities, and stylize them (via their distinctive color and form), suggesting an aestheticization of the park's social use that emulates and amplifies certain effects of visual social media. For one, they show a concern with recognition that echoes the preoccupation social media platforms have with precisely locating photographs: the fact that the same color of pink appears in all publications of the park administration, reinforces the chairs' association with the park so that wherever they are pictured, they definitively locate the contents of the photograph. For another, these are chairs that want to be photographed. Particularly in the context of the park's periodic and event-based as opposed to continuous use - which means the chairs are frequently empty - and the predominance of open prospects as opposed to enclosed spaces within it, their bright color draws photographic attention: they appear on Instagram, Flickr and elsewhere, both as subjects in themselves, and as instantly recognizable elements within broader views of the landscape (see Figures 3 and 4, as well as my collection of re-posted Instagramimages, @pinkchairsofgrandpark). Given their association with the park's name via its pink-themed signs and publications, the more these photographs of the chairs are circulated on social media, the more the park becomes recognizable as a socially and/or aesthetically interesting place.

The communicative functioning of these chairs could be seen as an update on a longstanding capacity of public landscapes such as parks - that is, to facilitate activities deemed morally beneficial or politically useful (such as the carefully controlled "social mixing" so beloved of the nineteenth-century public parks movement), and to signify the cultural value of those activities and naturalize the social hierarchies inscribed within them. ${ }^{40}$ Similarly, in a photographically inclined culture, the photogenic nature of the chairs could be viewed simply as a means of signaling the cultural value of the social interactions they enable. Except there is an additional, noteworthy development here: the distribution of the chairs throughout the landscape, and their bright color, means that they communicate in these ways regardless of whether they are of interest to the photographer. He or she need not recognize and attend to a particular view or focal point; their appearance in photographs does not depend on the landscape being read or interpreted in any particular way (see Figure 5). This means they can make a contribution to the visibility of the landscape, and perhaps even its social significance (given the association of 


\section{Amps}
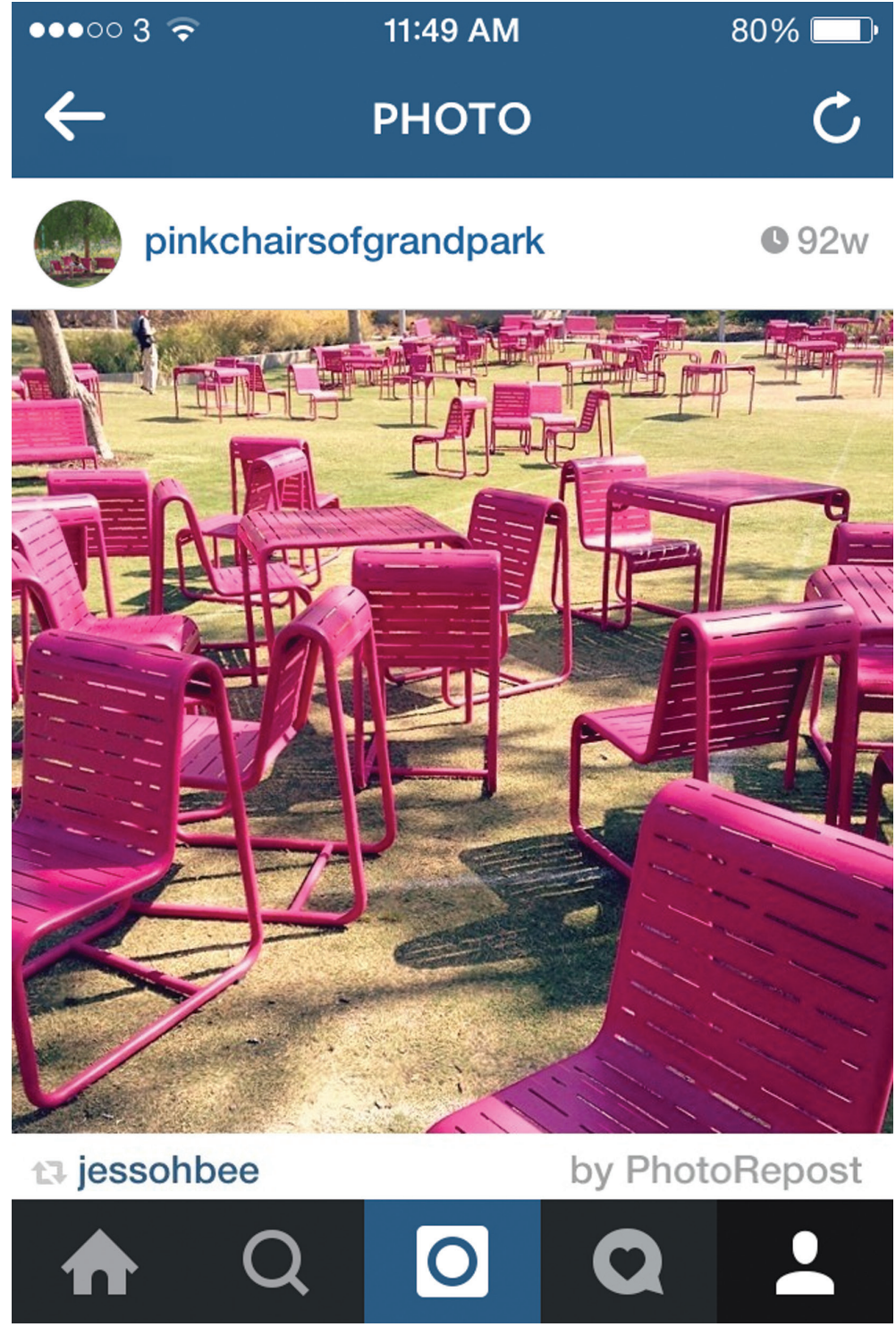

Figure 3: Screen shot of re-posted Instagram image, originally by @jessohbee.

park chairs with particular social activities), without conscious intervention by viewing subjects.

This strikes me as a form of re-mediation that departs from what we otherwise expect of photographic engagements with landscape (that is, its use as a pleasing backdrop for other subjects, or as a source of scenic views). Similar to 


\section{Amps}

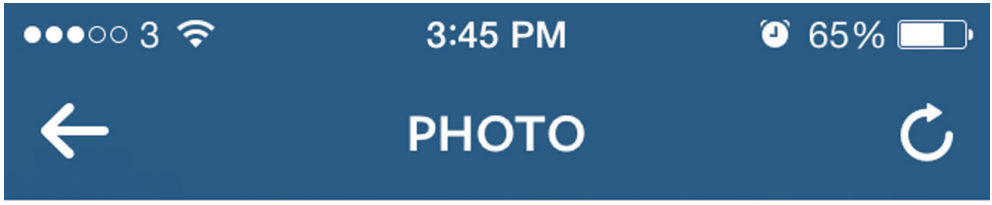

\section{pinkchairsofgrandpark}

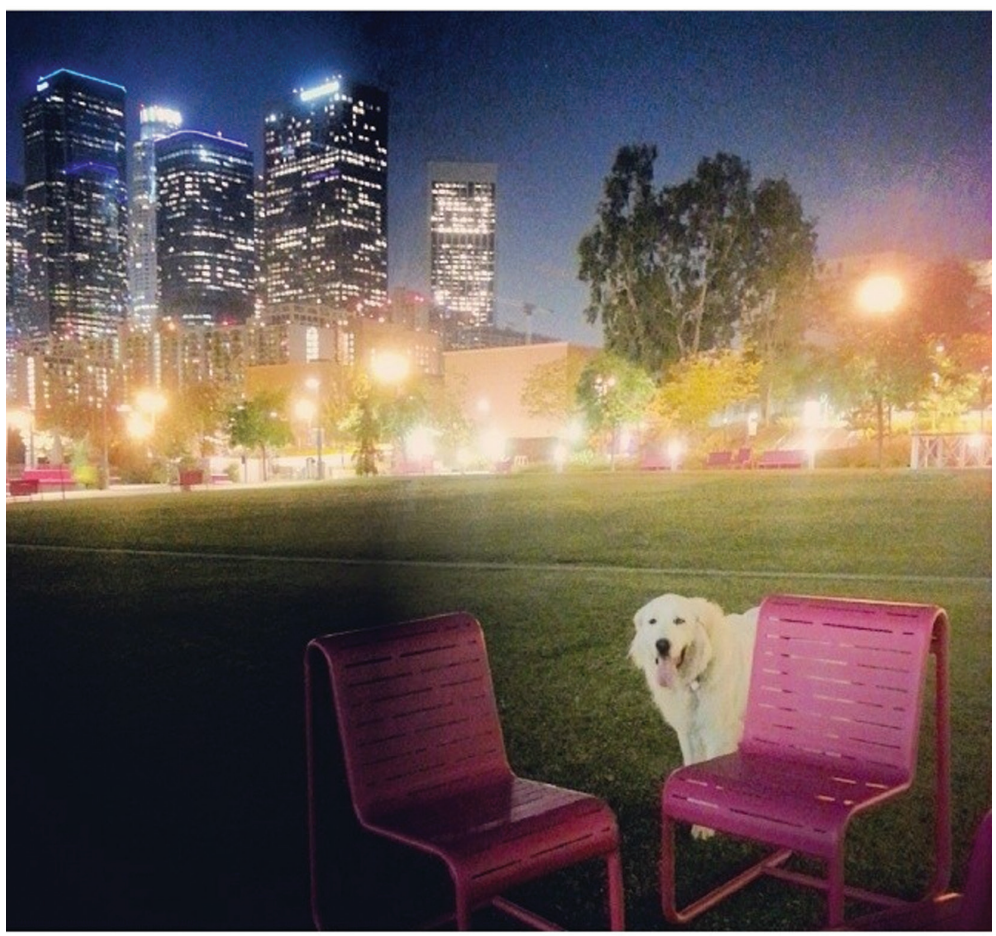

\section{nhtanesa}

by PhotoRepost

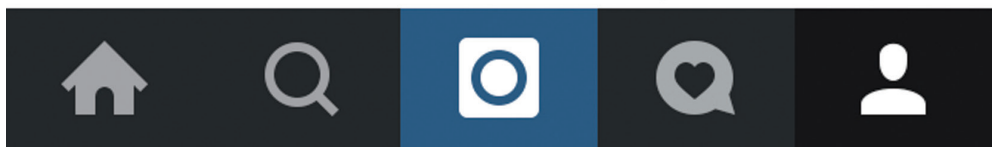

Figure 4: Screen shot of re-posted Instagram image, originally by @ nhtanesa.

the way Instagram photographs are seen to speak as opposed to represent or narrate their meaning, photographs of the park containing pink chairs communicate a location and its socio-cultural significance regardless of the nature or degree of the photographer's engagement with the landscape. The existing association of the chairs with the park (via the color pink), together with all 


\section{Amps}
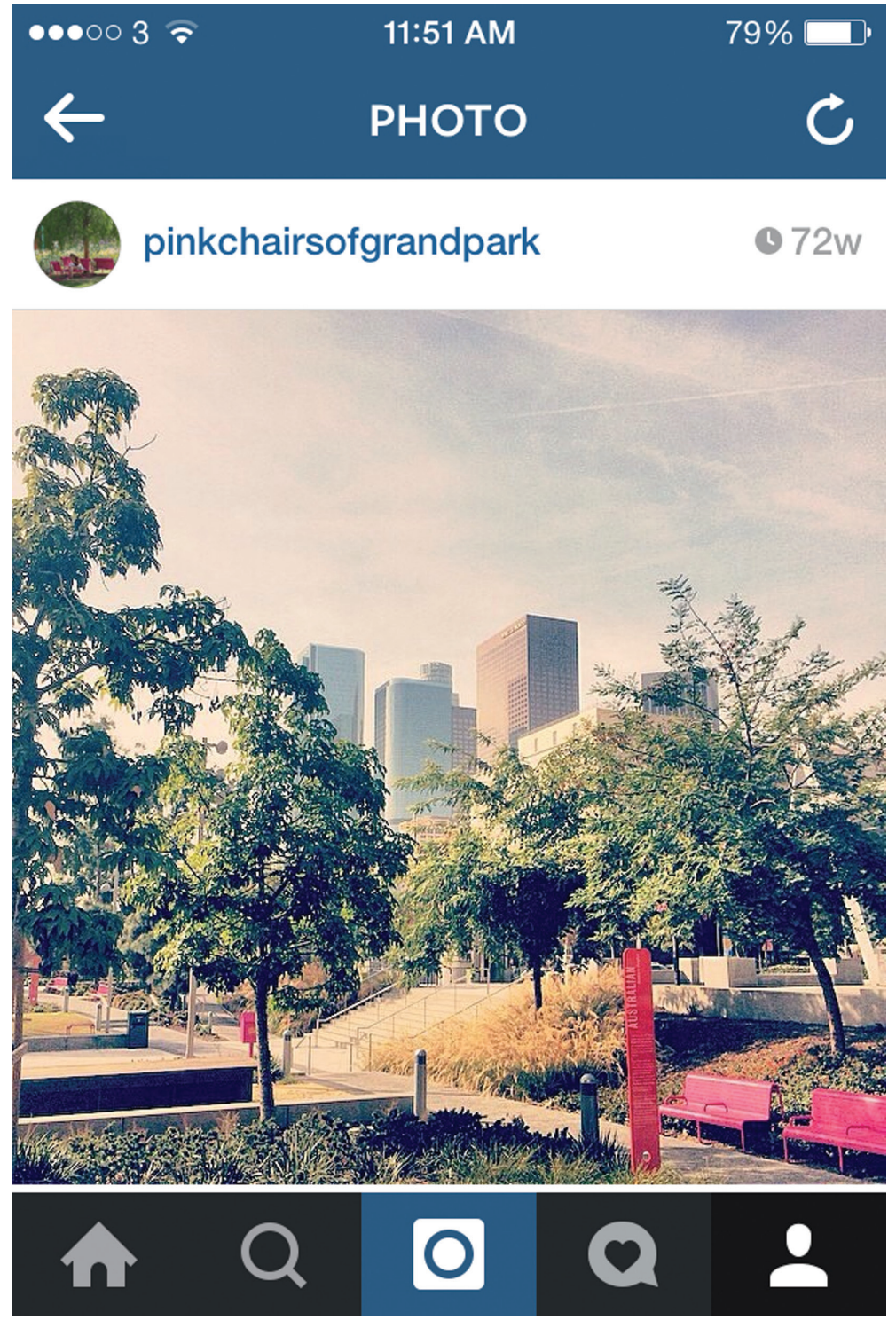

Figure 5: Screen shot of re-posted Instagram image, originally by @manfromnor.

they connote - about design, leisure and urban sociability - is reinforced by the simple fact of appearing in a social media posting.

The question of what is visible in a given time and place - that is, what people notice and attend to - is shaped in a myriad of half-concealed ways. This is true not only in the sense of formal processes of mediation (such as 


\section{Amps}

schooling, marketing, branding and so on), and the way spaces and buildings are designed, but also in the sense of broader discourses of public life (regarding what it is important to have, or to prevent in a public park, whose needs are to be served there, and so on), and taken-for-granted socio-cultural practices and visual technologies. ${ }^{41}$ It is therefore possible - as is often the case with "new" media - that the circulation of photographs of pink chairs on Instagram does not point to a new process of re-mediation, but rather to a shift in existing relations of seeing (and not seeing) that is made conspicuous by new technologies and practices. Nonetheless, the intentional but relatively unreflective production of those photographs, enables them to reveal aspects of the technical and social specificity of the landscape's visibility. This in turn provides an opportunity to interrogate the political implications of what is seen and not seen in the park. Specifically, and especially when viewed through the lens of social media, photographs of the chairs remind us that ways of seeing the world are always accompanied by specific socialities.

The photogenic qualities of Grand Park's pink chairs go along with their frequent emptiness, for they do not make such striking photographs, or contribute in the same way to certain scenic views when occupied. They would also not be as reliably unoccupied were they to appear in a less comprehensively open landscape: the fact that the park's so-called middle plane is consistently empty, limits opportunities for concealment and makes it conducive to roundthe-clock surveillance, which in turn ensures that the use of the chairs for sleeping and other "undesirable" activities is highly unlikely. ${ }^{42}$ As such, their aesthetization of particular ways of being together in public, goes along with a way of controlling who can be together, under what circumstances. While many Angelinos seem happy to have a downtown public park that does not host gatherings of homeless people (in contrast to nearby Pershing Square), or political demonstrations (such as Occupy LA's encampment outside City Hall in 2011), it is worth pointing out that the visibility of tourism, leisure activities and cultural events in the park depends on the relative invisibility of certain social problems and political inequities (since the vibrancy of the former is seen to depend on the absence of the latter). ${ }^{43}$ Grand Park has been branded by its administration as "the park for everyone," but it achieves its photogenic and culturally (if not economically) diverse social life at the cost of certain exclusions.

\section{Conclusion}

Already in 2013, Instagram co-founder Kevin Systrom claimed that the platform had changed how we see the world. ${ }^{44}$ Especially when considered as part of a larger socio-cultural development facilitated by a variety of social media platforms, I believe that this was more than just hyperbole. However, as the example of Grand Park demonstrates, the influence of social media such as Instagram is not accomplished through the platform on its own, but through its inextricable involvement with other media forms, such as that of designed 
landscape. As I have attempted to briefly demonstrate here, attending to the way different media forms interact with and inform the socio-perceptual functioning of designed landscape can help us to see more clearly how it shapes site-specific visibilities, as well as some of their social and political implications. This may in turn allow for the identification of specific factors or features constraining the extent to which a given public space can function in a dynamic or inclusive manner.

In this respect, Grand Park may not provide the best site for pursuing such questions further. Given the historic problems with crime, drug-use and homelessness in downtown Los Angeles, administrators and local politicians have consciously prioritized cleanliness, safety and attractiveness of the park over other concerns (e.g., inclusiveness or political vibrancy). ${ }^{45}$ However, in other public landscapes, where there is an interest in facilitating more openended interactions, or where users participate more actively in shaping or caring for it, being able to identify how socio-political visibilities and invisibilities are reinforced or contested may provide a means of devising interventions to improve the functioning of such spaces.

For example, what appears in photographs of a given landscape and what does not? Might certain (apparently) photographic or aesthetic conventions precluding the representation of certain qualities, people or activities, point toward conflicted social relations (e.g., prejudice against certain groups)? Or do they reveal a disconnection between the intentions of a design, and the values and priorities of users (e.g., in parks that include naturalized areas subsequently viewed as neglected)? I contend that, through the pursuit of questions such as these, a deliberately intermedial landscape criticism can enhance what public landscapes make available to collective awareness and processes of change.

When Instagram's API was publicly accessible, there was a potential to build the capacity for such a criticism through informal, collaborative means for example, through the development of apps to enable systematic searching and collection of images of a given landscape by users. ${ }^{46}$ Now that this is no longer true, an intermedial criticism depends on more formal, institutionally supported relationships (e.g., between landscape architects or critics, media scholars, and app developers), or the re-purposing of existing tools. For example, while Flickr gathers a different cross-section of landscape photographs than Instagram (i.e., containing more professional content), it allows users to build maps and galleries of other users' photographs - a capacity that has already been repurposed to media-artistic ends. ${ }^{47}$ Such projects hint at the pedagogical potential of an intermedial landscape criticism, suggesting that critics and architects might collaborate with students as well as media-savvy users of public landscapes to highlight, engage and challenge some of the processes of mediation and re-mediation in which landscape participates. In the context of such efforts, we can begin to image public landscapes as sites of collective self-reflexivity as well as of social interaction and symbolic projection - in other words, as places where we might catch a glimpse of the limited 
and provisional nature of otherwise taken-for-granted ways of seeing life in the city, and begin to imagine alternatives.

\section{Notes}

1 Diane Harris and, D. Fairchild Ruggles, eds., Sites Unseen (Pittsburgh, PA: University of Pittsburgh Press, 2007); Mukerji, Chandra, Territorial Ambitions and the Gardens of Versailles (Cambridge, New York and Melbourne: Cambridge University Press, 1997); Simon Pugh, Garden-Nature-Language (Manchester, UK: Manchester University Press, 1988).

2 W. J. T. Mitchell, "Imperial Landscape," in Landscape and Power, 2nd edition, ed. W. J. T. Mitchell (Chicago and London: University of Chicago Press, 2002), 5-34. Elen Deming, "Value Added: An Introduction," in Values in Landscape Architecture and Environmental Planning, ed. Elen Deming (Baton Rouge: Louisiana State University Press, 2015a), 1-29.

3 Denis Cosgrove, "Landscape and the European Sense of Sight," in Handbook of Cultural Geography, ed. Kay M. Anderson, Mona Domosh, Steven Pile, and Nigel Thrift (London: Sage, 2003), 249-67; John R. Stilgoe, "Popular Photography, Scenery Values and Visual Assessment," Landscape Journal 3,2 (1984): 111-122.

4 Galen Cranz, The Politics of Public Park Design: A History of Urban Parks in America (Cambridge, MA: MIT Press, 1982).

5 Lynn A. Staeheli, and Don Mitchell, The People's Property? Power, Politics, and the Public (New York: Routledge, 2008).

6 Elen Deming, "Finding Center: Design Agency and the Politics of Landscape," in Values in Landscape Architecture and Environmental Planning, ed. Elen Deming (Baton Rouge: Louisiana State University Press, 2015) 220-36.

7 For a survey of the field, see Heywood and Sandywell, 2012.

8 Ash Amin, "Collective Culture and Urban Public Space," City 12,1 (2008): 15.

9 D. W. Meinig, "The Beholding Eye: Ten Versions of the Same Scene," in The Interpretation of Ordinary Landscapes: Geographical Essays, ed. D. W. Meinig (New York: Oxford University Press, 1979), 33-48.

10 Michel Conan, ed., Contemporary Garden Aesthetics, Creations and Interpretations (Washington, DC: Dumbarton Oaks Research Library and Collection, 2007); see also Susan Herrington, On Landscapes (New York and London: Routledge, 2009).

11 For example, see Erin Despard, "A materialist media ecological approach to studying urban media in/of place," in Innovative Methods in Media and Communication Research, eds. Anne Kaun and Sebastian Kubitschko (Cham, Switzerland: Palgrave Macmillan, 2016), 37-58;; Ben Shirtcliff, "Big Data in the Big Easy: How Social Networks Can Improve the Place for Young People in Cities," Landscape Journal 34,2 (2015): 161-76; Patricia Toscano, "Instagram-City: New Media, and the Social Perception of Public Spaces," Visual Anthropology 30 (2017): 275-86.

12 For example, see Raz Schwartz and Nadav Hochman, "The Social Media Life of Public Spaces: Reading Places Through the Lens of Geo-Tagged Data," in Locative Media, ed. R. Wilken and G. Goggin (New York: Routledge, 2014): 52-65; T. H. Silva et al., "A Picture of Instagram is Worth a Thousand Words: 
Workload Characterization and Application," in Proceedings of the 2013 IEEE International Conference on Distributed Computing in Sensor Systems (IEEE, 2013), 123-32; J. Zhang, H. Zhao, and Y. Xie, "Follow You From Your Photos," in Proceedings of the 2013 IEEE International Conference on Green Computing and Communications and IEEE Internet of Things and IEEE Cyber, Physical and Social Computing (IEEE, 2013), 985-92.

13 For example, see David Crandall and Noah Snavely, "Networks of Photos, Landmarks and People," Leonardo 44 (2011): 240-3; Nadav Hochman and Len Manovitch, "Zooming into an Instagram City," First Monday 18,7 (2013), accessed August 19, 2018, http://bds.sagepub. com/content/1/2/2053951714546645.

14 Mitchell Schwarzer, "Computation and the Impact of New Technologies on the Photography of Architecture and Urbanism," Architecture_media_politics_society 11,4 (2017): 1-18.

15 Crandall and Snavely, "Networks"; Schwartz and Hochman, "Social Media Life."

16 Silva et al., "Picture of Instagram."

17 Zhou Bolei, Liu Liu, Aude Oliva, and Antonio Torralba, "Recognizing City Identity via Attribute Analysis of Geo-Tagged Images," in Computer Vision ECCV 2014, ed. D. Fleet, T. Pajdla, B. Schiele, and T. Tuytelaars. Lecture Notes in Computer Science, vol. 8691 (Springer, 2014), 519-34.

18 Yen Chen, John R. Parkins, and Kate Sherren, "Using Geo-Tagged Instagram Posts to Reveal Landscape Values Around Current and Proposed Hydroelectric Dams and their Reservoirs," Landscape and Urban Planning 170 (2018): 283-92.

19 Schwarzer, "Computation," 6 . Though he does note their utility for monitoring changes to buildings or sites over time - a project which would seem to require a certain degree of comparative qualitative analysis by humans as opposed to relying solely on computer-driven analytics.

20 danah boyd and Kate Crawford, "Critical Questions for Big Data," Information, Communication and Society 15,5 (2012): 662-79; Matthew W. Wilson, "Morgan Freeman is Dead and Other Big Data Stories," Cultural Geographies 22,2 (2015): $345-9$.

21 Although the age of users varies with platforms, younger people are much more likely to be regular users of social media. For example, with respect to visual social media, see Lee Raine, Joanna Brenner, and Kirsten Purcell, "Photos and Videos as Social Currency Online," PEW Internet and American Life Project (Washington: Pew Research Center, 2012), accessed August 19, 2018. http://www. pewinternet.org/2012/09/13/photos-and-videos-as-social-currency-online/.

22 Geospatial metadata, which features prominently in many studies, is especially problematic, since many users choose not to provide this information upon posting, and the data that is automatically associated with photographs pertains to the site of upload, which is not necessarily where the photograph was taken.

23 This is to suggest that social media data provides a measure of representational activities that are not necessarily representative of anything else. Wilson, "Morgan Freeman is Dead."

24 Ibid. 
25 Marshall McLuhan, Understanding Media: The Extensions of Man (New York, Toronto and London: McGraw-Hill Book Company, 1964).

26 Andrew Boulton and Matthew Zook, "Landscape, Locative Media and the Duplicity of Code," in The Wiley-Blackwell Companion to Cultural Geography ed. Nuala C. Johnson, Richard H. Schein, and Jamie Winders (John Wiley \& Sons Ltd., 2013), 437-51.

27 There is not enough space here to trace the full lineage of this term. I note simply that while it originated with members of the Toronto School of media studies (e.g., Harold Innis, Marshall McLuhan and Walter Ong), it has been used somewhat differently in other fields - for example, literary studies (e.g., in the work of N. Katherine Hayles and Ursula Heise) - and has recently seen a more expansive use in new materialist media studies (e.g., Matthew Fuller, Jussi Parikka).

28 Ursula Heise, "Unnatural Ecologies: The Metaphor of the Environment in Media Theory," Configurations 10 (2002): 148-169.

29 McLuhan, Understanding Media.

30 Ibid, 63.

31 Douglas Nickel, "Photography, Perception, Landscape," in America in View: Landscape Photography 1865 to Now, ed. Douglas Nickel (Providence, RI: RSID, 2012), 22; see also Denis Cosgrove, Social Formation and Symbolic Landscape (Madison, WI: The University of Wisconsin Press, 1998), especially pp. 257-64.

32 Ron J. Giblett, "Preface, Part One," in Photography and Landscape, ed. R. J. Giblett and J. Tolonen (Bristol and Chicago: Intellect, 2012), 15-26.

33 Nav Hochman, "The Social Media Image," Big Data and Society 1,2 (2014): 1-15; Susan Murray, "Digital Images, Photo-Sharing, and Our Shifting Notions of Everyday Aesthetics," Journal of Visual Culture 7,2 (2008): 147-63.

34 Daniel Rubenstein and Katrina Sluis, "A Life More Photographic," Photographies 1,1 (2008): 9-28.

35 Ibid; see also Frosh, Paul, "Rhetorics of the Overlooked: On the Communicative Modes of Stock Photography," Journal of Consumer Culture 2,2 (2002): 171-96.

36 Erin Despard, "Photographic social media, designed urban landscapes and placebased visibilities: In search of friction," Journal of Aesthetics and Culture 7 (2015), accessed November 11, 2018, http://dx.doi.org/10.3402/jac.v7.28242.

37 This analysis included comparisons between the number of likes for photographs in the subset compared to those in the sample as a whole, the number of followers the users posting those photographs had, and so on. While not included in the results, this analysis enabled certain observations about constraints on the utility of Instagram data for critical or social scientific research. These are discussed in a working paper found at www.communicativelandscapes.com.

38 The breakdown was approximately $10 \%$ videos, and $90 \%$ photos. A hashtag rather than location-based search was chosen because the latter will return photos taken outside the park but uploaded in its vicinity, and also fail to capture those uploaded after the user had left the park.

39 It also enabled compliance with Instagram's rules of use, which stipulate that photographs cannot be stored offline. At the same time, permission was obtained for use of all the photographs. 
40 Hazel Conway, Public Parks (Buckinghamshire, Shire Publications Ltd: 1996).

41 Andrea Mubi Brighenti, Visibility in Social Theory and Social Research (Basingstoke, UK: Palgrave Macmillan: 2010).

42 As press coverage of the park's opening emphasized, concerns about drug use, sleeping in the park, and protest encampments led to a commitment by the city to a "firm and vigilant" approach to security. See S. Allen, "Grand Park Downtown Opens with a Flourish - and Hopes of Growing," LA Times (online edition), July 27, 2012, accessed August 19, 2018, http://articles.latimes.com/2012/jul/27/local/ la-me-grand-park-20120727/.

43 G. Holland, "L.A.'s Urban Parks: For the Homeless Too?" LA Times, August 31, 2013, accessed August 19, 2018, http://articles.latimes.com/2013/aug/31/local/ la-me-homeless-parks-20130901/.

44 Olivier Laurent, "'Instagram Has Changed How People See the World,' Claims Co-Founder Kevin Systrom," British Journal of Photography [online] October 2013, accessed August 19, 2018, http://www.bjp-online.com/2013/10/instagramhas-changed-the-way-people-see-the-world-claims-co-founder-kevin-systrom/.

45 As one administrator put it: "We don't want to throw protesters out . . but we want this to be a park for everyone to enjoy," Allen, "Grand Park Downtown."

46 See Despard, Photographic Social Media.

47 For example, see some of the maps created by Eric Fischer. Accessed August 19, 2018, https://www.flickr.com/photos/walkingsf/albums/.

\section{Bibliography}

Allen, S. "Grand Park Downtown Opens with a Flourish - and Hopes of Growing." LA Times (online edition), July 27, 2012). http://articles.latimes.com/2012/jul/27/ local/la-me-grand-park-20120727.

Amin, Ash. "Collective Culture and Urban Public Space." City 12,1 (2008): 5-24.

Bolei, Zhou, Liu Liu, Aude Oliva, and Antonio Torralba, "Recognizing City Identity via Attribute Analysis of Geo-Tagged Images." In Computer Vision - ECCV 2014, edited by D. Fleet, T. Pajdla, B. Schiele, and T. Tuytelaars. Lecture Notes in Computer Science, vol. 8691 (Springer, 2014), 519-34.

Boulton, Andrew, and Matthew Zook, "Landscape, Locative Media and the Duplicity of Code." In The Wiley-Blackwell Companion to Cultural Geography edited by Nuala C. Johnson, Richard H. Schein, and Jamie Winders (John Wiley \& Sons Ltd., 2013), 437-51. boyd danah, and Kate Crawford, "Critical Questions for Big Data," Information, Communication and Society 15,5 (2012): 662-79.

Brighenti, Andreas Mubi. Visibility in Social Theory and Social Research. Basingstoke, UK: Palgrave Macmillan, 2010.

Chen, Yen, John R. Parkins, and Kate Sherren, "Using Geo-Tagged Instagram Posts to Reveal Landscape Values Around Current and Proposed Hydroelectric Dams and their Reservoirs," Landscape and Urban Planning 170 (2018): 283-92.

Conan, Michel, ed. Contemporary Garden Aesthetics: Creations and Interpretations. Washington, DC: Dumbarton Oaks Research Library and Collection, 2007. Conway, Hazel. Public Parks. Buckinghamshire: Shire Publications Ltd, 1996. 
Cosgrove, Daniel. Social Formation and Symbolic Landscape. Madison, WI: The University of Wisconsin Press, 1998.

Cosgrove, Daniel. "Landscape and the European Sense of Sight." In Handbook of Cultural Geography, edited by Kay M. Anderson, Mona Domosh, Steven Pile, and Nigel Thrift, 249-67. London: Sage, 2003.

Crandall, David, and Noah Snavely, "Networks of Photos, Landmarks and People," Leonardo 44 (2011): 240-3; Nadav Hochman and Len Manovitch, "Zooming into an Instagram City," First Monday 18,7 (2013), accessed August 19, 2018, http://bds. sagepub. com/content/1/2/2053951714546645.

Cranz, Galen. The Politics of Public Park Design: A History of Urban Parks in America. Cambridge, MA: MIT Press, 1982.

Deming, Elen. "Value Added: An Introduction." In Values in Landscape Architecture and Environmental Planning, edited by Elen Deming, 1-29. Baton Rouge: Louisiana State University Press, 2015a.

Deming, Elen. "Finding Center: Design Agency and the Politics of Landscape." In Values in Landscape Architecture and Environmental Planning, edited by Elen Deming, 220-36. Baton Rouge: Louisiana State University Press, 2015.

Despard, Erin, "Photographic social media, designed urban landscapes and placebased visibilities: In search of friction," Journal of Aesthetics and Culture 7 (2015), accessed November 11, 2018, http://dx.doi.org/10.3402/jac.v7.28242.

Despard, Erin, "A materialist media ecological approach to studying urban media in/ of place," in Innovative Methods in Media and Communication Research, eds. Anne Kaun and Sebastian Kubitschko (Cham, Switzerland: Palgrave Macmillan, 2016), 37-58.

Giblett, Ron J. "Preface, Part One." In Photography and Landscape, edited by Ron J. Giblett and J. Tolonen, 15-26. Bristol and Chicago: Intellect, 2012.

Frosh, Paul. "Rhetorics of the Overlooked: On the Communicative Modes of Stock Photography." Journal of Consumer Culture 2,2 (2002): 171-96.

Harris, Diane, and D. Fairchild Ruggles, eds. Sites Unseen. Pittsburgh, PA: University of Pittsburgh Press, 2007.

Heise, Ursula. "Unnatural Ecologies: The Metaphor of the Environment in Media Theory." Configurations 10 (2002): 148-69.

Herrington, Susan. On Landscapes. New York and London: Routledge, 2009.

Heywood, Ian, and Barry Sandywell. "Critical Approaches to the Study of Visual Culture: An Introduction to the Handbook." In The Handbook of Visual Culture, edited by Ian Heywood and Barry Sandywell, 1-58. London: Berg Publishers, 2012.

Holland, Gale. "L.A.'s Urban Parks: For the Homeless Too?" LA Times (online). August 31, 2013, accessed August 19, 2018, http://articles.latimes.com/2013/aug/31/ local/la-me-homeless-parks-20130901.

Hochman, Nadav, and Len Manovitch, "Zooming into an Instagram City," First Monday 18,7 (2013), accessed August 19, 2018, http://bds.sagepub. com/content/1/2/2053951714546645.

Hochman, Nadav. "The Social Media Image.” Big Data and Society 1,2 (2014): 1-15.

Laurent, Olivier. "'Instagram Has Changed How People See the World,' Claims Co-Founder Kevin Systrom.” British Journal of Photography [online] October 
2013, accessed August 19, 2018, http://www.bjp-online.com/2013/10/instagram-haschanged-the-way-people-see-the-world-claims-co-founder-kevin-systrom/.

McLuhan, Marshall. Understanding Media: The Extensions of Man. New York, Toronto and London: McGraw-Hill Book Company, 1964.

Meinig, D.W. "The Beholding Eye: Ten Versions of the Same Scene." In The Interpretation of Ordinary Landscapes: Geographical Essays, edited by D. W. Meinig, 33-48. New York: Oxford University Press, 1979.

Mitchell, W. J. T. Imperial Landscape.” In Landscape and Power, 2nd edition, edited by W. J. T. Mitchell, 5-34. Chicago and London: University of Chicago Press, 2002.

Mukerji, Chandra. Territorial Ambitions and the Gardens of Versailles. Cambridge, New York and Melbourne: Cambridge University Press, 1997.

Murray, Susan. "Digital Images, Photo-Sharing, and Our Shifting Notions of Everyday Aesthetics." Journal of Visual Culture 7,2 (2008): 147-63.

Nickel, Don. "Photography, Perception, Landscape." In America in View: Landscape Photography 1865 to Now, edited by D. Nickel. Providence, RI: RSID, 2012.

Pugh, Simon. Garden-Nature-Language. Manchester, UK, Manchester University Press, 1988.

Raine, Lee, Joanna Brenner, and Kirsten Purcell. "Photos and Videos as Social Currency Online." PEW Internet and American Life Project. Washington: Pew Research Center, 2012, accessed August 18, 2018, http://www.pewinternet.org/2012/09/13/ photos-and-videos-as-social-currency-online/.

Rubenstein, Daniel, and Katrina Sluis. "A Life More Photographic." Photographies 1,1 (2008): 9-28.

Silva, T. H. et al., "A Picture of Instagram is Worth a Thousand Words: Workload Characterization and Application." In Proceedings of the 2013 IEEE International Conference on Distributed Computing in Sensor Systems, 123-32. IEEE, 2013.

Schwartz, Raz, and Nadav Hochman, "The Social Media Life of Public Spaces: Reading Places Through the Lens of Geo-Tagged Data." In Locative Media, edited by R. Wilken and G. Goggin (New York: Routledge, 2014): 52-65.

Schwarzer, Mitchell. "Computation and the Impact of New Technologies on the Photography of Architecture and Urbanism." Architecture_media_politics_society 11,4 (2017): 1-18.

Shirtcliff, Ben. "Big Data in the Big Easy: How Social Networks Can Improve the Place for Young People in Cities.” Landscape Journal 34,2 (2015): 161-76.

Staeheli, Lynn A. and Don Mitchell. The People's Property? Power, Politics, and the Public. New York: Routledge, 2008.

Stilgoe, John R. "Popular Photography, Scenery Values and Visual Assessment." Landscape Journal 3,2 (1984): 111-22.

Toscano, Patricia. "Instagram-City: New Media, and the Social Perception of Public Spaces," Visual Anthropology 30 (2017): 275-86.

Wilson, Matthew W. "Morgan Freeman is Dead and Other Big Data Stories." Cultural Geographies 22,2 (2015): 345-9. 